\title{
O efeito da utilização de ventiladores de teto no conforto térmico em salas de aulas com condicionamento híbrido em um local de clima quente e úmido
}

\author{
The impact of using ceiling fans on thermal comfort \\ conditions in mixed-mode classrooms in a hot and humid \\ climate
}

\begin{tabular}{|c|c|}
\hline & $\begin{array}{l}\text { Renata De Vecchi } \\
\text { Christhina Cândido } \\
\text { Roberto Lamberts } \\
\text { Resumo }\end{array}$ \\
\hline Renata De Vecchi & 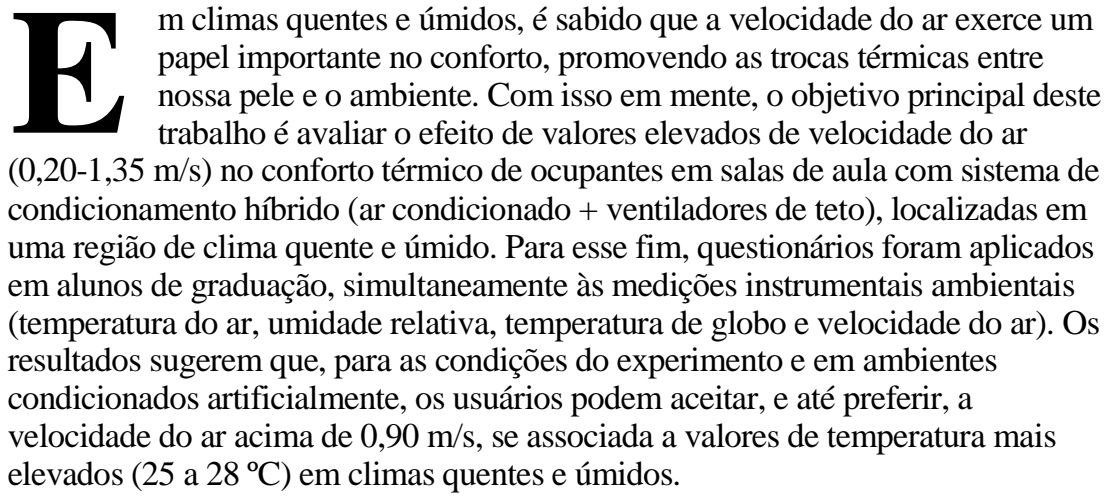 \\
\hline $\begin{array}{r}\text { Universidade Federal de Santa } \\
\text { Catarina } \\
\text { Florianópolis - SC - Brasil }\end{array}$ & Palavras-chave: Conforto térmico. Velocidade do ar. Climatização híbrida. \\
\hline & $\begin{array}{l}\text { Abstract } \\
\text { In hot and humid climates, it is known that air speed plays an important role in }\end{array}$ \\
\hline $\begin{array}{r}\text { Christhina Maria Cândido } \\
\text { University of Sydney } \\
\text { Sydney - Australia }\end{array}$ & $\begin{array}{l}\text { thermal comfort, promoting heat exchange between our skin and the environment. } \\
\text { With this in mind, this paper evaluates the effect of higher air speed values }(0.20 \text { - } \\
1.35 \mathrm{~m} / \mathrm{s} \text { ) on occupants' thermal comfort in mixed-mode classrooms (air }\end{array}$ \\
\hline $\begin{array}{r}\text { Roberto Lamberts } \\
\text { Universidade Federal de Santa } \\
\text { Catarina } \\
\text { Florianopolis - SC - Brasil }\end{array}$ & $\begin{array}{l}\text { conditioned + ceiling fans) located in a hot and humid climate. To this end, } \\
\text { questionnaires were administered simultaneously to instrumental measurements } \\
\text { (air temperature, globe temperature, air speed and humidity). Results suggest that } \\
\text { occupants of air-conditioned indoor environments in hot and humid climates could } \\
\text { accept, and even prefer, air speed values above } 0.90 \mathrm{~m} / \mathrm{s} \text {, but only if they're }\end{array}$ \\
\hline Recebido em 15/04/13 & associated with higher temperature set-points $\left(25-28^{\circ} \mathrm{C}\right)$ \\
\hline Aceito em $08 / 10 / 13$ & Thermal comfort. Air movement. Hybrid-mode cooling. \\
\hline
\end{tabular}




\section{Introdução}

Ao longo dos últimos anos, muitos estudos têm discutido a influência da velocidade do ar e os limites de temperatura aceitos nessas condições. Em climas quentes e úmidos, é sabido que a ventilação exerce um papel importante no conforto, promovendo as trocas térmicas através da convecção e evaporação entre o corpo e o ambiente. A contribuição do movimento do ar na remoção do calor através da pele varia de acordo com a temperatura e umidade. Entre os estudos que alimentam a discussão a respeito desse assunto, é possível encontrar limites de velocidade do ar que variam de 0,5 a $3,00 \mathrm{~m} / \mathrm{s}$ (TANABE; KIMURA, 1994; ARENS et al., 1998; KHEDARI et al., 2000; TOFTUM, 2004; CÂNDIDO et al., 2011a; CÂNDIDO; DE DEAR; LAMBERTS, 2011). Nicol (2004) explica que o efeito causado pela ventilação permite a tolerância de temperaturas até $4{ }^{\circ} \mathrm{C}$ mais elevadas, sendo que, quando combinada com a utilização de ventiladores, essa tolerância pode se desenvolver em até $2{ }^{\circ} \mathrm{C}$. De Dear (2011) afirma que, sob condições climáticas quentes, o estímulo causado pela velocidade do ar quando se busca restabelecer o conforto térmico é positivo, e neste caso a movimentação do ar não só é bem-vinda como também desejada pelos usuários (CÂNDIDO et al., 2011a).

No entanto, tais estímulos causados pela velocidade do ar são tradicionalmente indicados para edifícios passivos, onde a ventilação natural predomina durante todo o ano. Em edificações condicionadas artificialmente, o limite de velocidade do ar estipulado pela ISO 7730 (INTERNATIONAL..., 2005) varia de 0 a 0,40 $\mathrm{m} / \mathrm{s}$ para temperaturas na faixa de 18 a $26^{\circ} \mathrm{C}$. A mais recente versão da ASHRAE 55 (AMERICAN..., 2010) apresenta um método alternativo para ambientes com velocidade do ar elevadas, desde que exista o controle local restrito a um número de ocupantes (a cada grupo de no máximo seis pessoas), ou restrito a determinada área (a cada $84 \mathrm{~m}^{2}$ ). Nesse caso, a velocidade do ar pode chegar até $1,20 \mathrm{~m} / \mathrm{s}$ quando a temperatura operativa estiver dentro de uma faixa de 27,5 até $30,5^{\circ} \mathrm{C}$.

No Brasil as normas existentes estão desatualizadas e restringem a velocidade do ar a pequenos intervalos que vão de 0 a $0,80 \mathrm{~m} / \mathrm{s}$. A norma de segurança e saúde do Ministério do Trabalho NR 17 (ABNT, 1990), que discorre sobre as condições ambientais de trabalho e ergonomia, limita a temperatura ambiental a um intervalo de temperatura efetiva entre 20 e $23{ }^{\circ} \mathrm{C}$, e velocidade do ar não superior a $0,75 \mathrm{~m} / \mathrm{s}$, sem nenhuma referência que estabelece se esses limites são indicados para ambientes condicionados ou não. A NBR 16401/2 (ABNT, 2008) estipula intervalos de temperatura operativa no verão (de 22 a $26{ }^{\circ} \mathrm{C}$ ) de acordo com a umidade relativa do ar, e a velocidade do ar não deve ultrapassar $0,20 \mathrm{~m} / \mathrm{s}$ para sistemas de distribuição de ar convencional, ou $0,25 \mathrm{~m} / \mathrm{s}$ para sistemas de distribuição de ar com fluxo de deslocamento. O problema relacionado às normas de conforto térmico no Brasil e os limites de velocidade do ar por elas empregados foi discutido por Cândido et al. (2011b) e, mais recentemente, por Lamberts et al. (2013). Neste último relatório publicado em 2013 , os autores apresentam uma nova proposta de norma de conforto térmico para o Brasil com base no texto da ASHRAE 55 (AMERICAN..., 2010) e em uma revisão dos experimentos de campo já realizados no país.

Apesar de o método alternativo da ASHRAE 55 (AMERICAN..., 2010) estimular a utilização de valores mais altos de velocidade do ar, quando combinados com a utilização do ar condicionado, pouco se avançou nessa área. No Japão, set-points acima de $28{ }^{\circ} \mathrm{C}$ estão sendo estimulados por campanhas como o Cool Biz e o Setsuden (TANABE; IWAHASHI; TSUSHIMA, 2012), e um estudo realizado por Indraganti, Ooka e Rijal (2013) verificou que os níveis de aceitabilidade nessas condições podem ultrapassar a marca de $85 \%$, até mesmo sob valores baixos de velocidade do ar. Arens et al. (2009) afirmam que em ambientes climatizados artificialmente a faixa de temperatura comum para níveis de aceitabilidade alterna entre 16,5 e $25,5^{\circ} \mathrm{C}$. Em edificações com sistemas híbridos, observam-se temperaturas e velocidades mais altas quando a ventilação natural opera (DEUBLE; DE DEAR, 2012). No entanto, durante os períodos em que o ar condicionado está em uso prevalece o sistema "estático", e o setpoint é fixado com base no modelo do PMV/PPD de Fanger (1970), o que automaticamente acaba restringindo a velocidade do ar.

Nesse contexto, o objetivo deste artigo é avaliar o efeito de valores elevados de velocidade do ar (entre 0,20 e $1,35 \mathrm{~m} / \mathrm{s}$ ) no conforto térmico de ocupantes em salas de aula com sistema de condicionamento híbrido (ventiladores de teto e ar condicionado). Os resultados deste artigo fazem parte da dissertação de mestrado de De Vecchi (2011), que utilizou um método de trabalho similar ao de Cândido (2010), porém adaptado para as particularidades do clima de Florianópolis e para as condições da edificação estudada.

190 De Vecchi, R.; Cândido, C.; Lamberts, R. 


\section{Método}

A principal característica do método utilizado neste levantamento de campo é a proximidade, no tempo e espaço, entre as variáveis ambientais medidas e as respostas subjetivas dos ocupantes (questionários). As medições foram realizadas durante quatro meses de estações distintas (março - verão/outono, abril e maio - outono, e novembro - primavera) em salas de aula localizadas no campus da Universidade Federal de Santa Catarina, em Florianópolis $\left(27^{\circ} \quad 40^{\prime}\right.$ S $)$ Florianópolis, segundo a classificação de Köppen, é uma cidade caracterizada por um clima subtropical úmido, com verões em que a temperatura média varia entre 21 e $29^{\circ} \mathrm{C}$ e de 13 a $22^{\circ} \mathrm{C}$ durante os períodos de inverno (GOULART; LAMBERTS; FIRMINO, 1998). A umidade relativa do ar é alta durante todo o ano (acima de $80 \%$ ), e não existe estação seca. O maior volume de chuvas ocorre de Janeiro a Março, e o menor entre Julho e Agosto (precipitação anual média de $1521 \mathrm{~mm}$ ).

Durante os quatro meses do experimento de campo, 544 estudantes participaram da pesquisa, o que resultou em 2.292 questionários. Normalmente, as salas de aula operam com um sistema híbrido, combinando sistemas ativos (ar condicionado de janela), ventilação mecânica (ventiladores de teto) e ventilação passiva. Tais salas oferecem ainda oportunidades adaptativas para manutenção da temperatura interna, como a abertura de janelas e o acionamento dos ventiladores de teto e do ar condicionado (Figura 1). No entanto, durante os experimentos solicitou- se aos ocupantes que mantivessem as janelas fechadas e os ventiladores de teto sempre ligados, o que possibilitou a realização de mapas de velocidade do ar localizada, que era constantemente alta (entre 0,8 e $1,2 \mathrm{~m} / \mathrm{s}$ ) em pontos logo abaixo dos ventiladores.

\section{Usuários}

Alunos de diversos cursos de graduação foram voluntários nesta pesquisa. As medições ocorreram com maior frequência na sala de aula 01, por esta apresentar uma quantidade maior de ventiladores de teto e, consequentemente, uma quantidade maior de pontos com velocidade do ar elevada (2.026 dados provenientes da sala de aula 01, e 481 da sala de aula 02). Os dados antropométricos dos usuários podem ser observados na Tabela 1 , e a Figura 2 apresenta a porcentagem de usuários dos sexos feminino e masculino que participaram do estudo. Os valores do isolamento da vestimenta ( clo) e do metabolismo (met) foram estimados de acordo com a ISO 7730 (AMERICAN..., 2005) Anexos C e B respectivamente. Os estudantes vestiam roupas típicas de verão e meia estação, que variaram entre 0,22 a $0,89 \mathrm{clo}$, sendo o valor médio no dia mais quente próximo de $0,30 \mathrm{clo}$, e no dia mais frio, de 0,70 clo. Durante as aulas a atividade metabólica era de aproximadamente 70 $\mathrm{W} / \mathrm{m}^{2}$. Os valores de clo foram estimados considerando-se um adicional de 0,01 clo para o isolamento das cadeiras de salas de aula, conforme previsto pela ISO 7730 (AMERICAN..., 2005), Anexo C, e os ocupantes eram livres para adaptar sua vestimenta conforme a condição do ambiente.

Figura 1 - Representação em planta e configuração das salas de aula onde foram realizados os experimentos

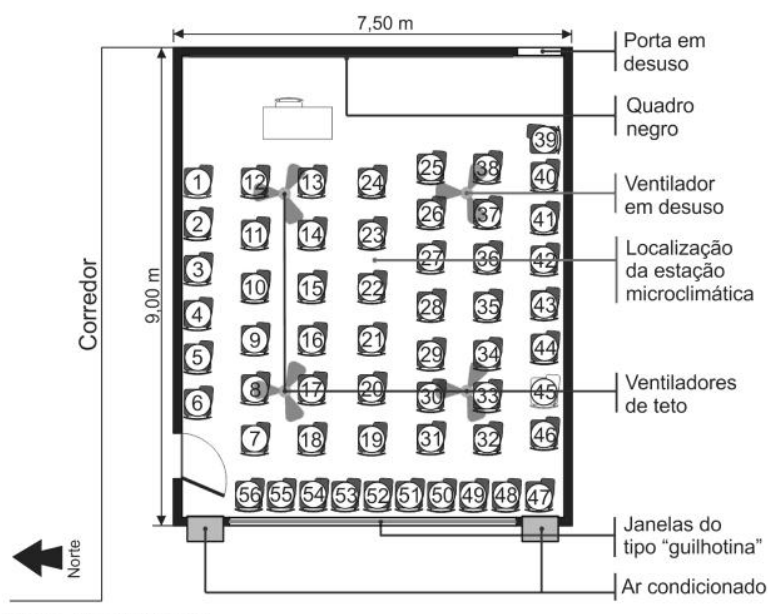

Sala de Aula 01

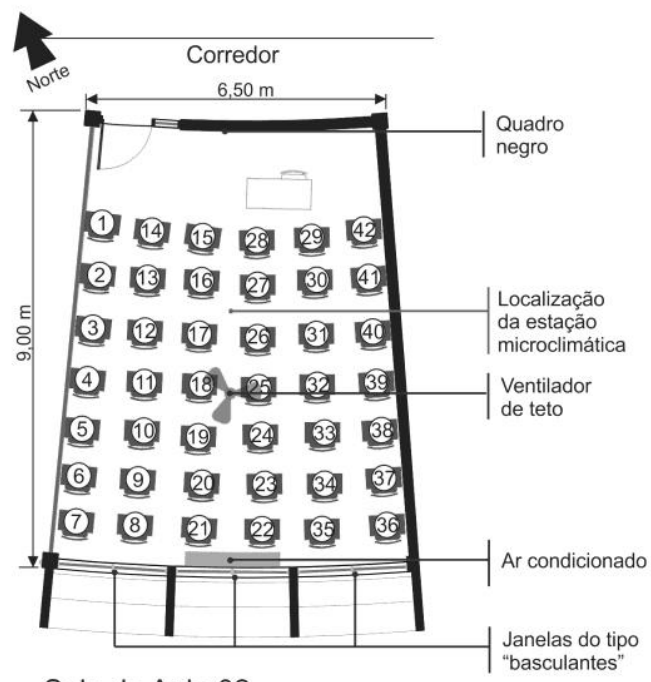

Sala de Aula 02 
Tabela 1 - Características antropométricas dos ocupantes

\begin{tabular}{l|c|c|c|c}
\hline & Mín. & Máx. & Média & Desvio p. \\
\hline Idade (anos) & 21 & 47 & 21,2 & 3,4 \\
Peso (kg) & 40 & 116 & 65,7 & 12,4 \\
Altura (m) & 1,50 & 1,95 & 1,72 & 0,1 \\
\hline
\end{tabular}

Figura 2 - Distribuição entre sexo dos ocupantes

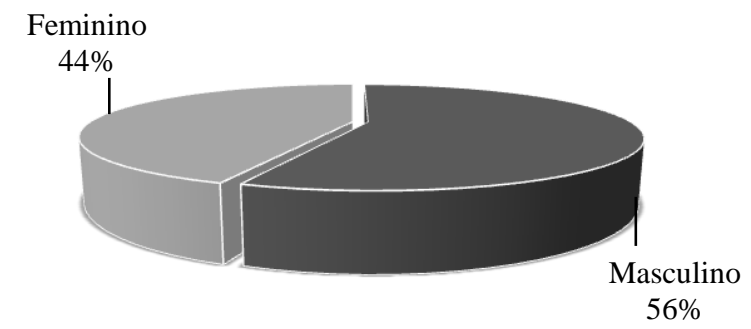

\section{Questionários}

O questionário focou no conforto e na aceitabilidade térmica e da velocidade do ar dos ocupantes (Quadro 1). De maneira complementar, o questionário também incluiu perguntas relacionadas à preferência térmica, da velocidade do ar e sistema de condicionamento (histórico térmico e exposição prévia aos ambientes com ar condicionado). $\mathrm{O}$ questionário foi organizado em quatro partes:

(a) dados antropométricos dos estudantes e atividades metabólicas antes e durante $\mathrm{o}$ experimento;

(b) preferência das estratégias de climatização (incluindo o ar condicionado, a ventilação natural e a utilização de ventiladores de teto) e exposição prévia aos ambientes com ar condicionado;

(c) sensação, preferência e aceitabilidade térmica;

(d) aceitabilidade e preferência do movimento do ar.

A discussão dos resultados levantados a partir dos questionários foi realizada com base na escala sétima de sensações térmicas de Fanger (1970), compreendendo valores entre -3 (muito frio) e +3 (muito calor).

\section{Instrumentos de medição}

Temperatura do ar, umidade relativa, temperatura de globo e velocidade do ar foram medidas com precisão laboratorial por meio de uma estação microclimática desenvolvida pelo Laboratório de Meios Porosos e Propriedades Termofísicas da Universidade Federal de Santa Catarina (LMPT/UFSC), denominada Sensu (Figura 3a). O equipamento foi localizado próximo ao centro das salas de aula, a uma altura de $0,60 \mathrm{~m}$ do chão. As variáveis eram registradas a cada $5 \mathrm{~min}$, e todos os equipamentos foram testados e calibrados com antecedência.

Medições complementares e individuais de velocidade do ar foram efetivadas com o auxílio de um termoanemômetro portátil de fio quente, também desenvolvido pelo LMPT/UFSC. A Figura $3 \mathrm{~b}$ mostra o sensor fixado em uma haste com altura de $0,60 \mathrm{~m}$ do chão, o que impede qualquer influência do pesquisador no momento da medição.

As medições complementares visaram estabelecer intervalos individuais de velocidade do ar, incrementados mediante os ventiladores de teto e ar condicionado. Essas medições foram realizadas pontualmente em todas as carteiras dos alunos (Figuras 4 e 5) e em ambas as salas de aula com a presença dos alunos. Todas as medições foram repetidas cerca de três vezes, e em dias diferentes, sendo que durante toda a pesquisa o leiaute da sala era mantido rigorosamente. As medições também foram repetidas com $\mathrm{o}$ ar condicionado funcionando em conjunto com os ventiladores de teto, o que permitiu a construção de dois mapas de velocidade do ar: um para as análises quando só os ventiladores funcionavam, e outro para as análises quando o ar condicionado e os ventiladores de teto funcionavam juntos. Como as janelas estavam sempre fechadas durante as medições pontuais, e durante os experimentos com os alunos, sem que houvesse a influência da ventilação natural, assumiu-se que a velocidade do ar em cada carteira era constante e variava apenas com o acionamento do ar condicionado. Os valores individuais de velocidade do ar foram utilizados para o cálculo do SET, PMV/PPD e verificação pontual da aceitabilidade e preferência da velocidade do ar. 
Quadro 1 - Questões e alternativas de respostas dadas aos ocupantes conforme o questionário aplicado e as análises do artigo

\begin{tabular}{|c|c|}
\hline Questões & Alternativas fornecidas \\
\hline $\begin{array}{l}\text { Qual a opção que melhor reflete a } \\
\text { maneira como você está se sentindo } \\
\text { neste momento? }\end{array}$ & $\begin{array}{ll}\square & \text { Com muito calor } \\
\square & \text { Com calor } \\
\square & \text { Levemente com calor } \\
\square & \text { Neutro } \\
\square & \text { Levemente com frio } \\
\square & \text { Com frio } \\
\square & \text { Com muito frio } \\
\end{array}$ \\
\hline $\begin{array}{l}\text { Como você preferiria estar se sentindo } \\
\text { agora? }\end{array}$ & $\begin{array}{ll}\square & \text { Mais resfriado } \\
\square & \text { Não mudar } \\
\square & \text { Mais aquecido }\end{array}$ \\
\hline $\begin{array}{l}\text { Como você avalia a velocidade do ar } \\
\text { neste momento? }\end{array}$ & $\begin{array}{ll} & \text { Inaceitável - Pouca velocidade do ar } \\
\square & \text { Inaceitável - Muita velocidade do ar } \\
\square & \text { Aceitável - Pouca velocidade do ar } \\
\square & \text { Aceitável - Suficiente velocidade do ar } \\
\square & \text { Aceitável - Muita velocidade do ar } \\
\end{array}$ \\
\hline $\begin{array}{l}\text { Qual a sua preferência com relação à } \\
\text { velocidade do ar? }\end{array}$ & $\begin{array}{ll}\square & \text { Mais velocidade do ar } \\
\square & \text { Não mudar } \\
\square & \text { Menos velocidade do ar }\end{array}$ \\
\hline $\begin{array}{l}\text { Para você, este ambiente térmico é } \\
\text { aceitável? }\end{array}$ & $\begin{array}{l}\square \text { Sim } \\
\square \text { Não }\end{array}$ \\
\hline $\begin{array}{l}\text { Neste momento, como você classifica } \\
\text { este ambiente confortável? }\end{array}$ & $\begin{array}{ll}\square & \text { Confortável } \\
\square & \text { Desconfortável }\end{array}$ \\
\hline
\end{tabular}

Figura 3 - Equipamentos de medição

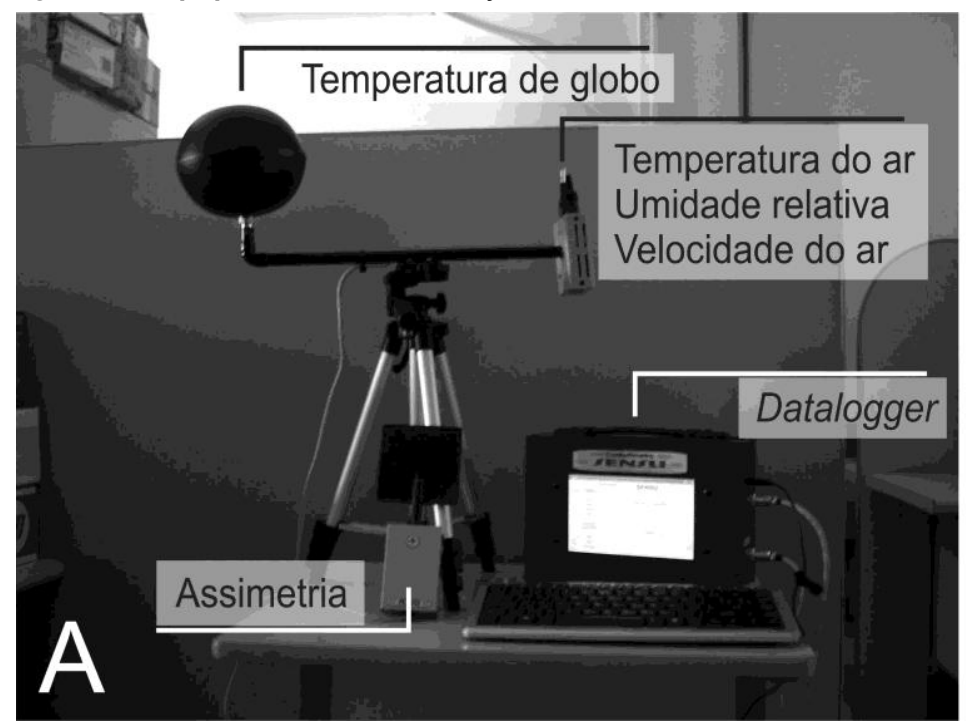

(a) Estação microclimática Sensu

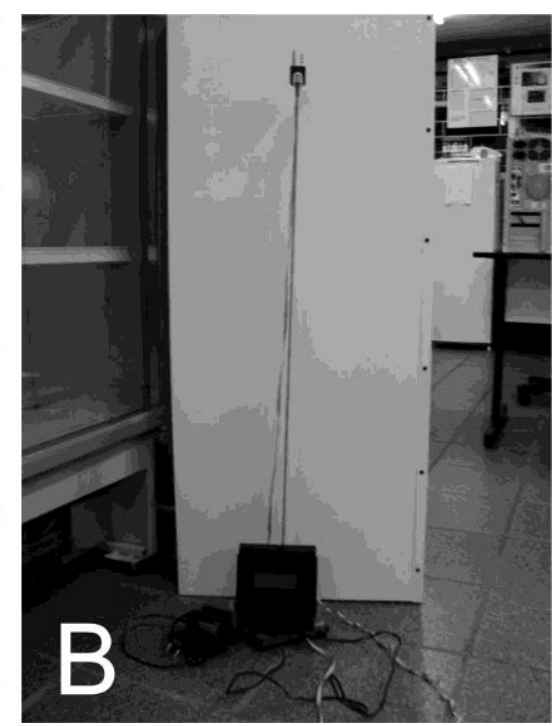

(b) Termoanemômetro portátil 
Figura 4 - Localização dos pontos de medição e representação dos mapas com a distribuição da velocidade do ar na sala de aula 01

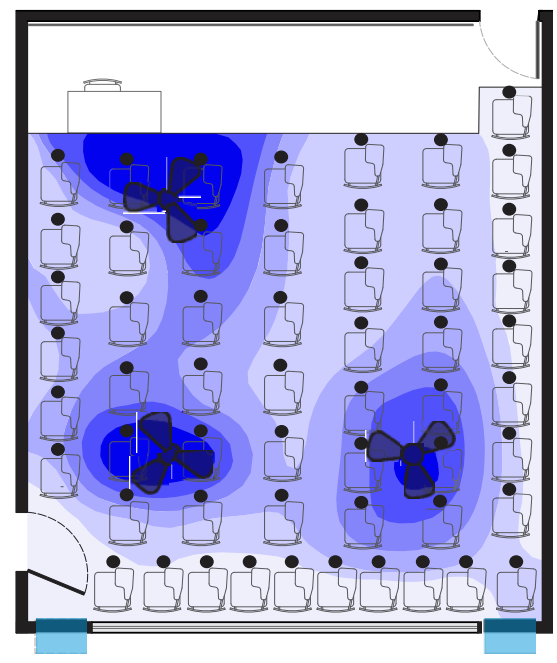

Medição com os ventiladores de teto ligados
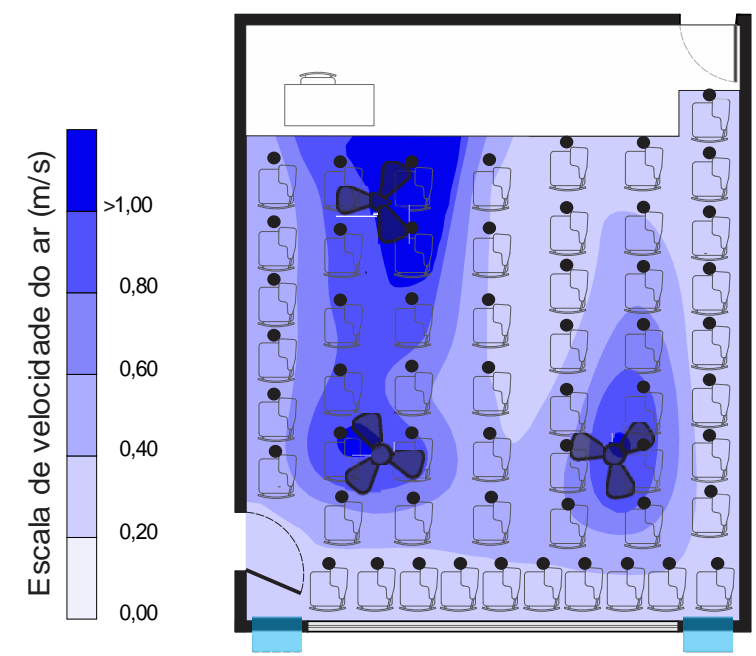

Medição com os ventiladores de teto e ar condicionado ligados

Nota: • pontos de medição da velocidade do ar.

Figura 5 - Localização dos pontos de medição e representação dos mapas com a distribuição da velocidade do ar na sala de aula 02

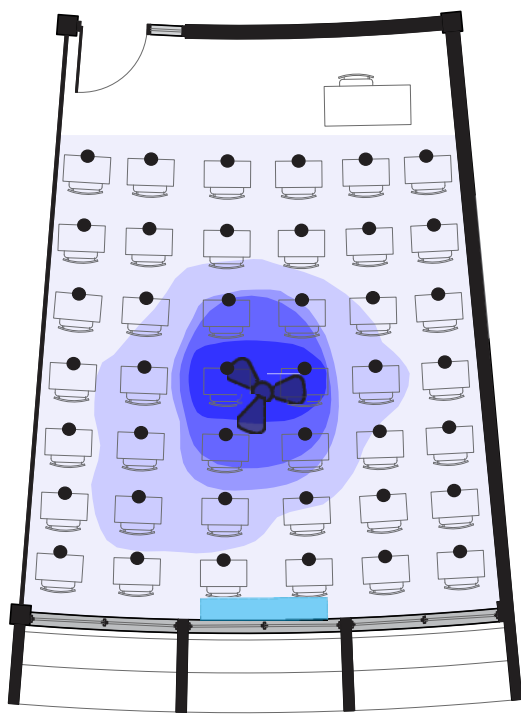

Medição com os ventiladores de teto ligados

Nota: • pontos de medição da velocidade do ar.

\section{Protocolo de medição e análise dos dados}

A pesquisa de campo durou em média 140 min em cada sala de aula, sendo os questionários aplicados em intervalos de $20 \mathrm{~min}$. Os usuários começaram a responder ao questionário $30 \mathrm{~min}$ após sua

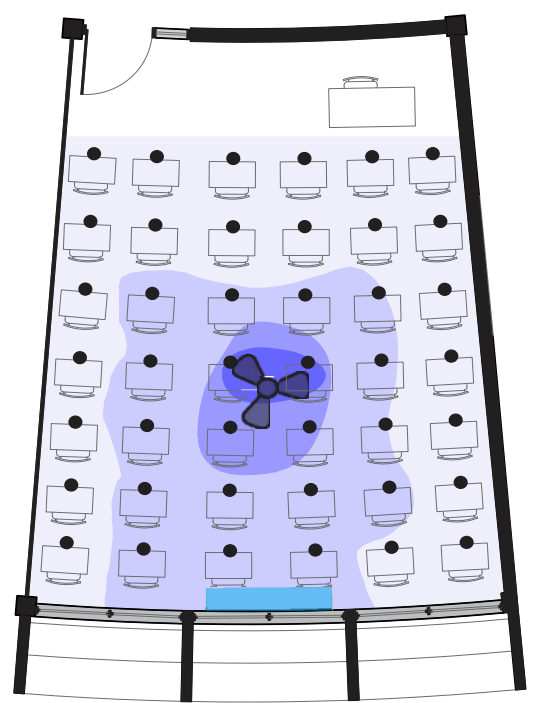

Medição com os ventiladores de teto e ar condicionado ligados

chegada, para evitar a influência da exposição aos transientes térmicos. Esse período também foi aproveitado para estabilizar os sensores e as medições das variáveis ambientais na estação microclimática e explicar os procedimentos e questionários aos ocupantes. A Figura 6 ilustra o protocolo de medição utilizado.

194 De Vecchi, R.; Cândido, C.; Lamberts, R. 
Figura 6 - Protocolo de medição adotado para a realização dos experimentos de campo

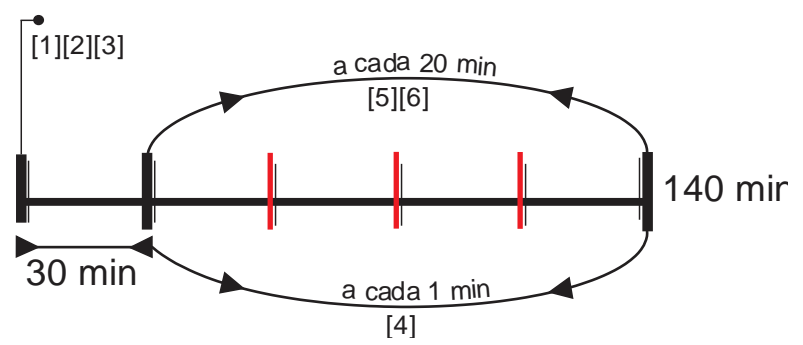

Nota: Legenda:

[1] Procedimentos preliminares;

[2] Acionamento da estação microclimática;

[3] Distribuição dos questionários ambientais;

[4] Medição contínua das variáveis ambientais;

[5] Avaliação térmica e da velicidade do ar (questionários); e

[6] Observação contínua do comportamento dos ocupantes.

Durante o experimento, as atividades dos alunos não foram interrompidas deliberadamente pelos pesquisadores, sendo livre e de critério dos alunos a adaptação das roupas e o acionamento dos equipamentos de refrigeração (ligar e desligar o ar condicionado). As janelas permaneceram fechadas durante todo o experimento, o que simulou o uso típico das salas durante os dias mais quentes. Os estudantes não foram autorizados a deixar a sala de aula durante os experimentos.

Os resultados foram tratados estatisticamente mediante análises de variância (ANOVA) e testes t de hipótese (Student t-test), com nível de significância $\mathrm{P}<0,05$. O banco de dados final foi organizado em planilhas eletrônicas, e os resultados foram cruzados entre si utilizando diferentes índices de conforto térmico, incluindo o PMV/PPD, temperatura efetiva padrão (SET) e a temperatura operativa.

Nos casos em que o valor da velocidade do ar ultrapassou a faixa de $0,50 \mathrm{~m} / \mathrm{s}$ e a temperatura do ar se encontrava fora do limite de 20 a $26{ }^{\circ} \mathrm{C}$, verificou-se o risco de desconforto causado pelas correntes de ar utilizando-se a Equação 1. Como a intensidade da turbulência do ar durante o experimento era desconhecida, utilizou-se o valor de $40 \%$, conforme recomendado pela ISO 7730 (INTERNATIONAL..., 2005).

$$
D R=\left(34-t_{a, l}\right)\left(\bar{v}_{a, l}-0,05\right)^{0,62}\left(0,37 \cdot \bar{v}_{a, l} \cdot T_{u}+3,14\right)
$$

Eq. 1

Onde:

$t_{a, l}$ é a temperatura local do ar em ${ }^{\circ} \mathrm{C}$ (variando entre 20 e $26^{\circ} \mathrm{C}$ );

$\overline{\mathrm{v}_{\mathrm{a}, \mathrm{l}}}$ é a velocidade local do ar, em m/s (acima de $0,5 \mathrm{~m} / \mathrm{s}) ; \mathrm{e}$

$T_{u}$ é a intensidade de turbulência, em $\%$.

\section{Resultados e discussão}

Para a análise, os dados foram divididos em dois grupos:

(a) quando somente os ventiladores de teto estavam ligados, $\mathrm{e}$

(b) quando os ventiladores de teto e o ar condicionado estavam ligados.

Dessa forma foi possível comparar e avaliar os dados obtidos para verificar se a velocidade do ar combinada com a utilização do ar condicionado nas condições do experimento de campo foi benéfica ou não.

Durante as medições a velocidade do ar nas salas de aula variou de 0,15 a $1,35 \mathrm{~m} / \mathrm{s}$, e houve pouca mudança na vestimenta dos alunos entre uma resposta e outra. A adaptação para o restabelecimento das condições de conforto térmico no ambiente ocorreu, na maior parte, através do acionamento do ar condicionado: em apenas 8 das 24 medições realizadas $\mathrm{o}$ ar condicionado foi acionado por um dos alunos durante o experimento. Nas outras 16 medições, 9 ocorreram com apenas os ventiladores de teto ligados, e nas outras 7 os alunos ligaram o ar condicionado antes mesmo da aula e do experimento começarem.

Os dados de temperatura externa foram cedidos pelo Laboratório de Engenharia de Processos de Conversão e Tecnologia de Energia (Lepten/UFSC), que possui uma estação meteorológica próximo ao bloco de Arquitetura e Urbanismo. A Tabela 2 sumariza os valores de velocidade do ar, temperatura operativa, temperatura efetiva padrão (SET) e temperatura externa do ar nas datas em que as medições foram realizadas. A maior amplitude observada ocorreu 
nos dados de temperatura externa do ar, sendo o mês de maio aquele que registrou a média de temperatura externa mais baixa $\left(19,1^{\circ} \mathrm{C}\right)$, e março, a média de temperatura externa mais alta $\left(23,2^{\circ} \mathrm{C}\right)$.

Os resultados indicam que a aceitabilidade térmica dos ocupantes pode estar relacionada à velocidade do ar, que aumentou à medida que o movimento do ar foi incrementado (Figura 7). É interessante observar que somente a partir de $0,9 \mathrm{~m} / \mathrm{s}$ é que a aceitabilidade térmica apresenta valores inferiores a $10 \%$. Tais resultados são similares àqueles encontrados por Cândido, De Dear e Lamberts (2011) na cidade de Maceió. Embora a condição climática e de operação do edifício se diferencie das condições deste experimento, os autores verificaram que a maior porcentagem de ocupantes que optou por não mudar a velocidade do ar se concentrou no intervalo de velocidade igual ou superior a $0,90 \mathrm{~m} / \mathrm{s}$. Quando esses dados foram desfragmentados e analisados grupo a grupo (Figura 8), observou-se que a aceitabilidade térmica nessas faixas de velocidade $(0,90$ e acima de $0,90 \mathrm{~m} / \mathrm{s}$ ) é maior quando o ar condicionado e os ventiladores de teto funcionam juntos, o que pode indicar que a utilização de valores de velocidade do ar acima daqueles estipulados pelas normas de conforto térmico para ambientes climatizados pode promover boas condições de aceitabilidade térmica, desde que combinados com set-points de temperatura adequados.

Tabela 2 - Variáveis climáticas internas e externas observadas durante o experimento

\begin{tabular}{l|c|c|c|c}
\hline & Mín. & Máx. & Média & Desv. Padrão \\
\hline Temperatura externa do ar $\left({ }^{\circ} \mathbf{C}\right)$ & 16,3 & 27,4 & 22,4 & 3,0 \\
Temperatura operativa $\left({ }^{\circ} \mathbf{C}\right)$ & 19,7 & 27,8 & 24,3 & 1,7 \\
Temperatura efetiva padrão $\left({ }^{\circ} \mathbf{C}\right)$ & 15,7 & 26,5 & 22,0 & 1,9 \\
Velocidade do ar interno $(\mathbf{m} / \mathbf{s})$ & 0,15 & 1,35 & 0,60 & 0,3 \\
\hline
\end{tabular}

Figura 7 - Aceitabilidade térmica dos ocupantes relacionada à velocidade do ar nas salas de aula

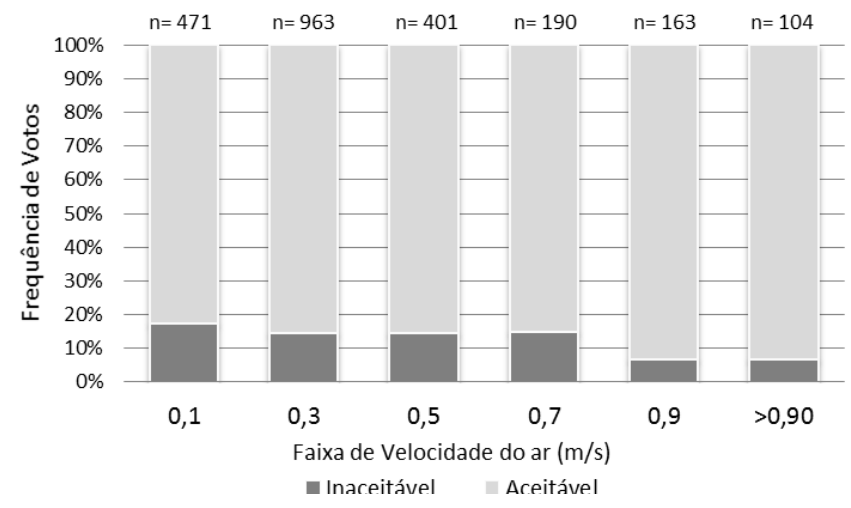

Figura 8 - Aceitabilidade térmica relacionada à velocidade do ar

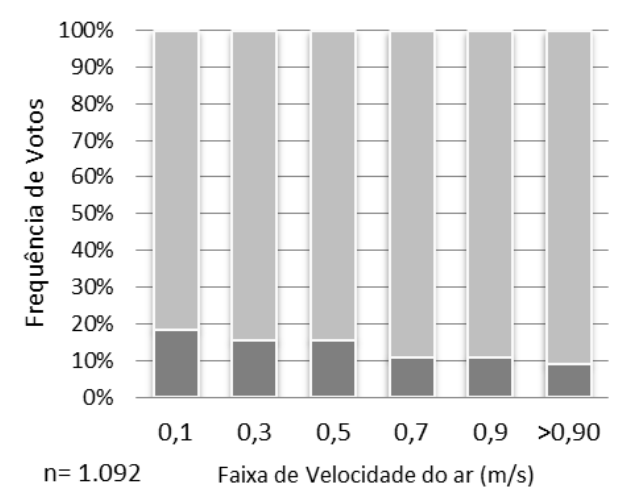

(a) Somente os ventiladores de teto estavam ligados

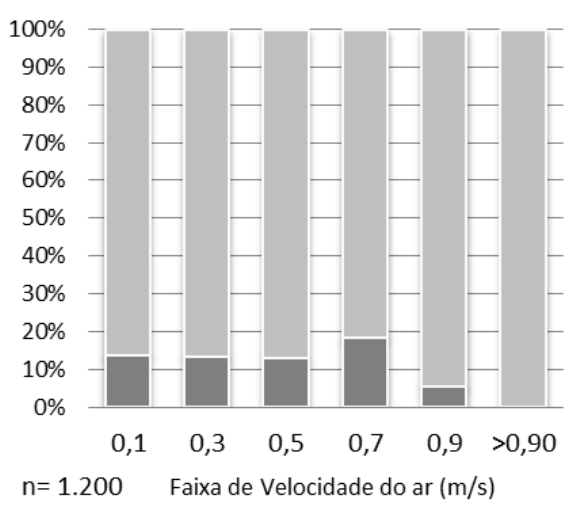

(b) Ventiladores de teto funcionando em conjunto com o ar condicionado

- Inaceitável $\square$ Aceitável

196 De Vecchi, R.; Cândido, C.; Lamberts, R. 
De forma complementar, a aceitabilidade térmica foi associada à aceitabilidade da velocidade do ar, indicando, através da Figura 9, que a inaceitabilidade (tanto térmica quanto pela velocidade do ar) ocorreu em maior porcentagem devido aos votos de ocupantes que relataram insuficiência na velocidade do ar (inaceitável por pouca velocidade do ar; aceitável, mas pouca velocidade do ar). Tais resultados são similares aos valores encontrados por Nicol e Roaf (1996), que observaram bons níveis de aceitabilidade térmica durante o verão em climas quentes quando a velocidade do ar atingiu a faixa de $1,5 \mathrm{~m} / \mathrm{s}$.

A aceitabilidade e a preferência pela velocidade do ar também foi analisada de acordo com a localização dos alunos dentro das salas de aula. Os votos foram ponderados de acordo com a frequência que os alunos utilizavam as carteiras e plotados nos mapas de velocidade do ar para facilitar a visualização da interação entre voto $x$ velocidade do ar x preferência e aceitabilidade da velocidade do ar. Ao observar a Figura 10 e a Figura 11 é possível verificar que a média dos votos de aceitabilidade da velocidade do ar esteve em sua maioria no intervalo "aceitável". Constatou-se uma frequência maior de votos de "pouca velocidade do ar" quando somente os ventiladores de teto estavam funcionando. Quando o ar condicionado foi ligado, observou-se que a frequência dos votos "pouca velocidade do ar" diminuiu significativamente, mantendo-se apenas nas áreas onde a velocidade do ar era inferior a $0,20 \mathrm{~m} / \mathrm{s}$. Tais resultados reforçam a ideia de que a utilização da velocidade do ar em ambientes climatizados artificialmente pode elevar os níveis de aceitabilidade, o que permite um ajuste incremental do set-point de temperatura de sistemas centrais de ar condicionado, e a consequente redução no consumo energético.

A utilização de valores mais altos de velocidade do ar permitiu avaliações relacionadas ao desconforto térmico localizado causado pelas correntes de ar indesejadas. Utilizando o Draught Rate (DR), observou-se que, entre os 2.292 dados coletados, apenas $11 \%$ dos valores se enquadraram nos limites para o cálculo estipulados pela ISO 7730 (INTRNATIONAL..., 2005). Em todos os casos em que se averiguou a taxa predita de pessoas insatisfeitas por correntes de ar, os resultados ultrapassaram a faixa de $60 \%$ (Figura 12). No entanto, quando os valores de aceitabilidade do movimento do ar dos usuários foram analisados para as mesmas faixas de velocidade do ar, observou-se um grande contraste com relação aos resultados obtidos de $D R$. Apenas uma pequena porcentagem dos usuários (12\% dos $11 \%$ dos votos analisados) classificou a velocidade do ar como "inaceitável”, e a grande maioria (88\%) classificou a velocidade do ar como "aceitável e suficiente". Tais resultados indicam que nos climas quentes e úmidos o uso da draught rate $(D R)$ é irrelevante, confirmando estudos anteriores (HUANG et al., 2013; MAKHOUL; GHALI; GHADDAR, 2013; ZHAI et al., 2013; CÂNDIDO et al., 2011a; ARENS et al., 2009).

\section{Figura 9 - Aceitabilidade térmica dos usuários associada aos votos de aceitabilidade da velocidade do ar}

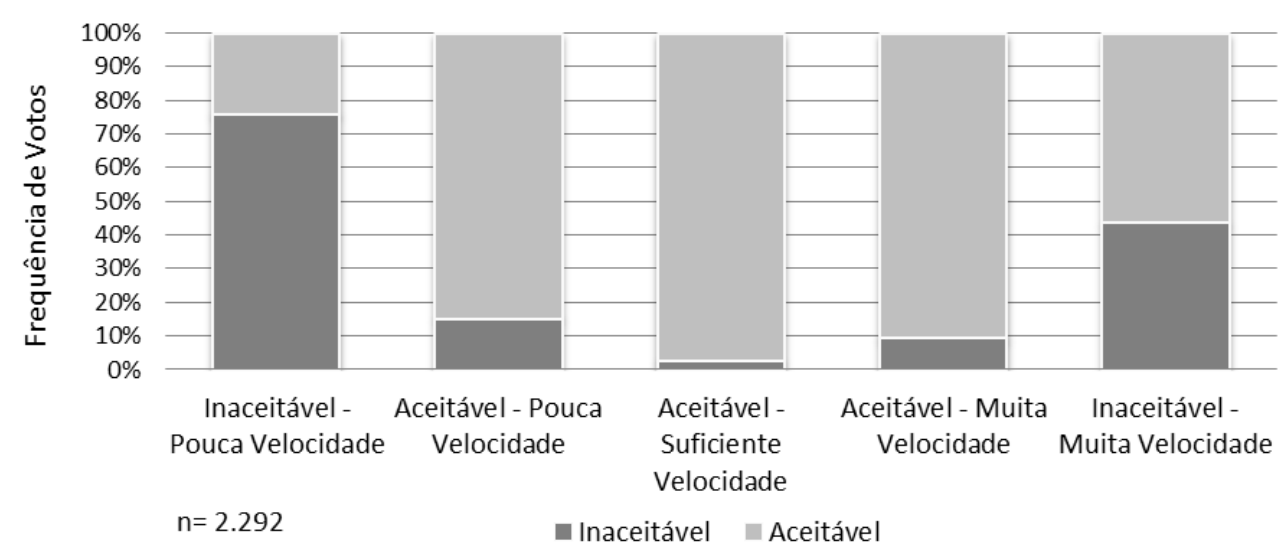


Figura 10 - Aceitabilidade da velocidade do ar associada à disposição dos usuários na sala de aula 01

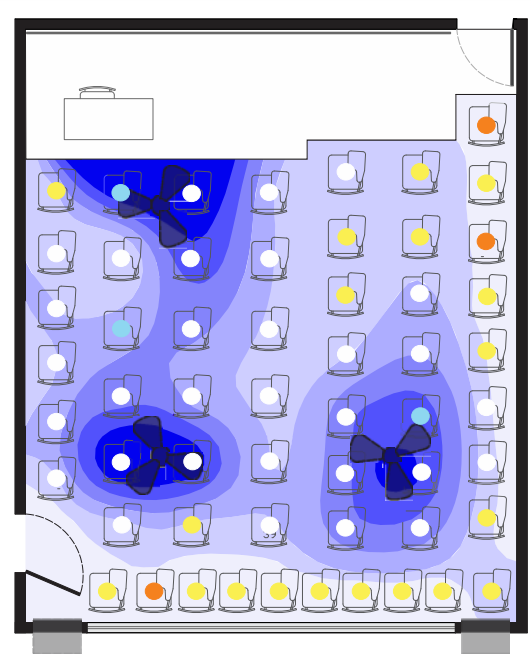

Sala 01

Sem ar condicionado

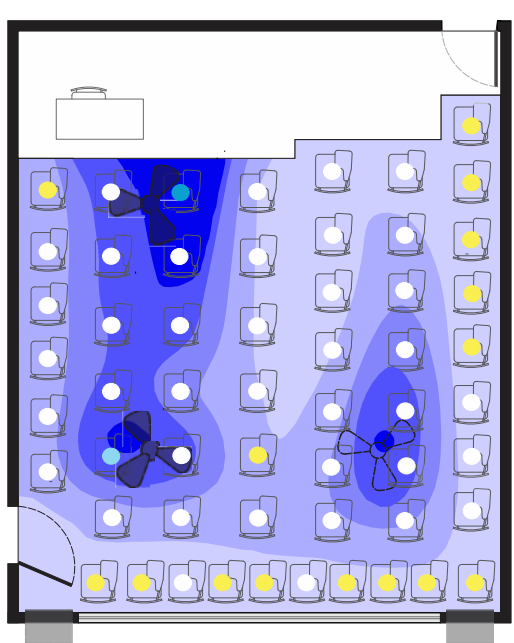

Sala 01

Com ar condicionado

Figura 11 - Aceitabilidade da velocidade do ar associada à disposição dos usuários na sala de aula 02

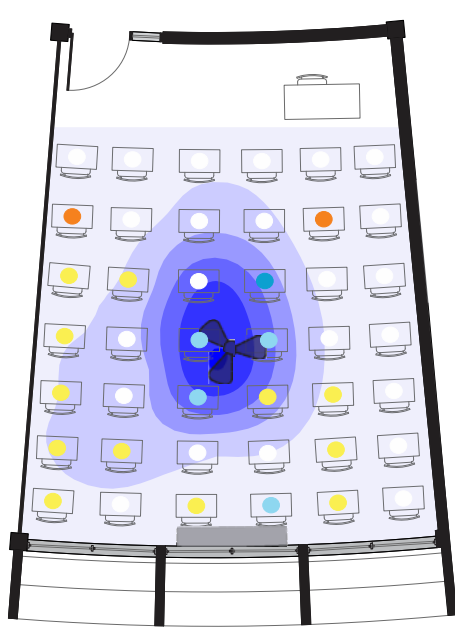

Sala 02

Sem ar condicionado

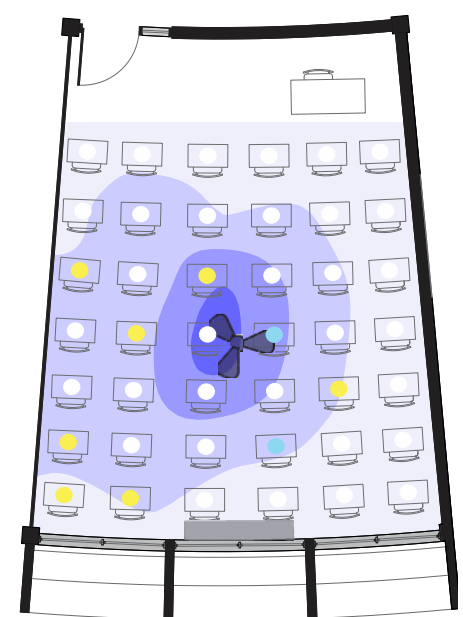

Sala 02

Com ar condicionado

Figura 12 - Taxa de desconforto térmico ocasionado pelas correntes de ar (DR) associada aos votos de aceitabilidade da velocidade do ar

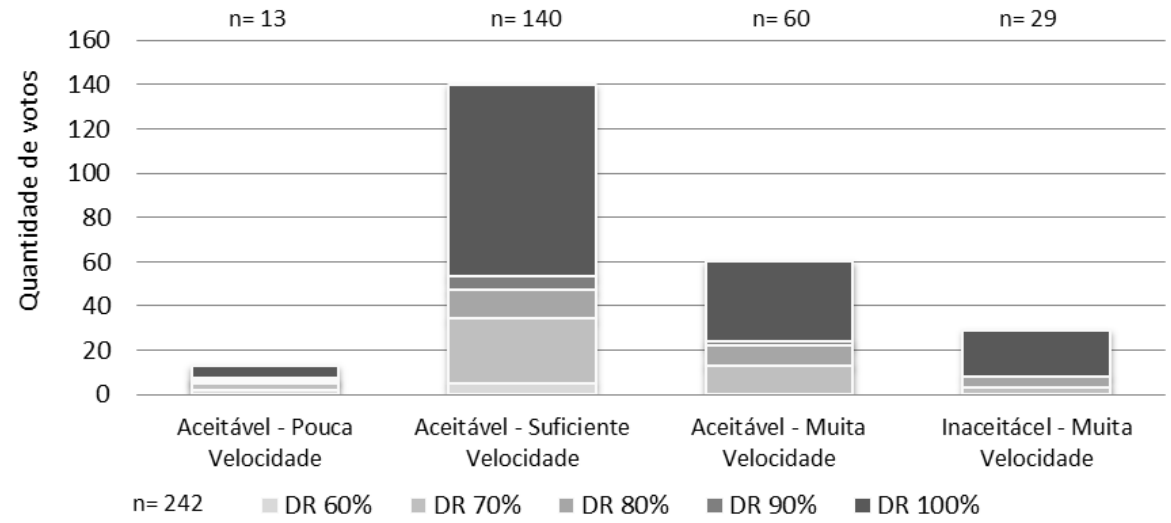

198 De Vecchi, R.; Cândido, C.; Lamberts, R. 
A mesma análise das Figura 10 e 11 foi realizada considerando-se os votos de preferência pela velocidade do ar (Figura 13 e Figura 14). Através dos mapas, nota-se que em ambas as salas existem usuários que ainda preferem valores mais altos de velocidade do ar, mesmo quando $\mathrm{o}$ ar condicionado está ligado. Quando os mapas de aceitabilidade e preferência são comparados, é possível observar que, em alguns pontos onde os ocupantes tiveram média de votos "suficiente velocidade do ar", ainda aparece a preferência por valores mais altos. O mesmo acontece com ocupantes que classificaram o local com o voto "pouca velocidade do ar", optando por não mudar essa condição. É interessante ressaltar ainda que usuários que afirmaram que a velocidade do ar, apesar de excessiva, era aceitável não optaram por diminuir tais valores.

Finalmente foram avaliadas as condições de conforto térmico das salas de aula considerando os dois grupos analisados (sala operada apenas com ventiladores de teto e sala operada com ventiladores de teto e ar condicionado juntos). As Figura 15a e 15b apresentam os resultados considerando a temperatura operativa das salas de aula, observando-se que a porcentagem maior de votos de desconforto ocorre no grupo A. Através da Figura 15b é possível afirmar que, quando a velocidade do ar é alta (acima de $0,80 \mathrm{~m} / \mathrm{s}$ ), a aceitabilidade térmica e o conforto tendem a crescer, podendo chegar a faixas de temperatura de até $28{ }^{\circ} \mathrm{C}$ nas condições em que o experimento foi realizado. Tais resultados condizem com pesquisas anteriores, em que a utilização da velocidade do ar (ar personalizado) permitiu faixas de temperatura confortáveis em ambientes climatizados artificialmente de 26 a $28{ }^{\circ} \mathrm{C}$ (SEKHAR et al., 2005; AMAI et al., 2007). É importante ainda observar que entre 21 e $25{ }^{\circ} \mathrm{C}$ foi possível obter conforto térmico utilizando-se apenas os ventiladores de teto.

\section{Conclusões}

Este artigo investigou os efeitos da velocidade do ar em salas de aula com sistemas híbridos de condicionamento. Os resultados indicam que a associação entre a velocidade do ar e o ar condicionado pode ser benéfica em regiões de climas quentes e úmidos. Dados levantados em Florianópolis demonstraram que os usuários podem aceitar, e até preferir, valores acima de 0,90 $\mathrm{m} / \mathrm{s}$, quando associados a valores de temperatura mais elevados.

\section{Figura 13 - Preferência pela velocidade do ar associada à disposição dos usuários na sala de aula 01}

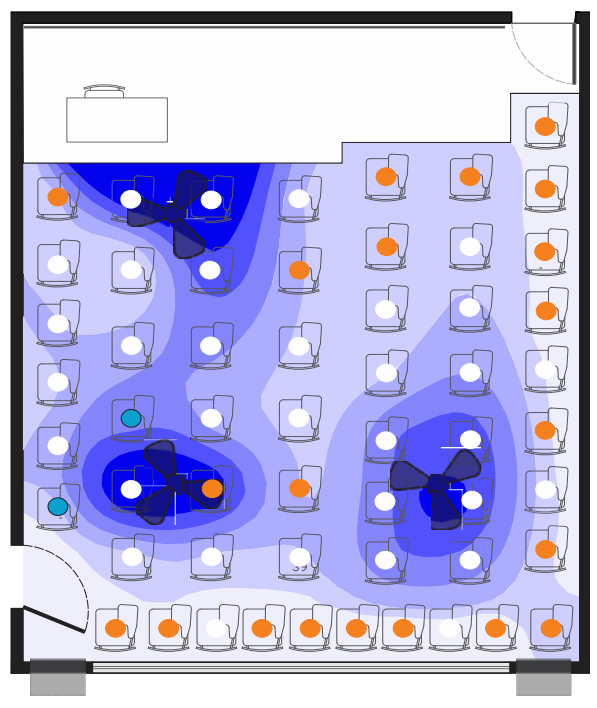

Sala 01

Sem ar condicionado

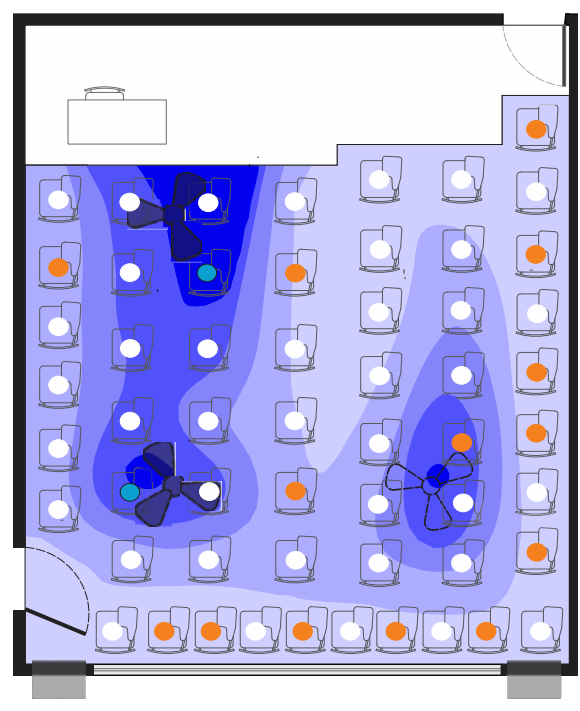

Sala 01

Com ar condicionado 
Figura 14 - Preferência pela velocidade do ar associada à disposição dos usuários na sala de aula 02

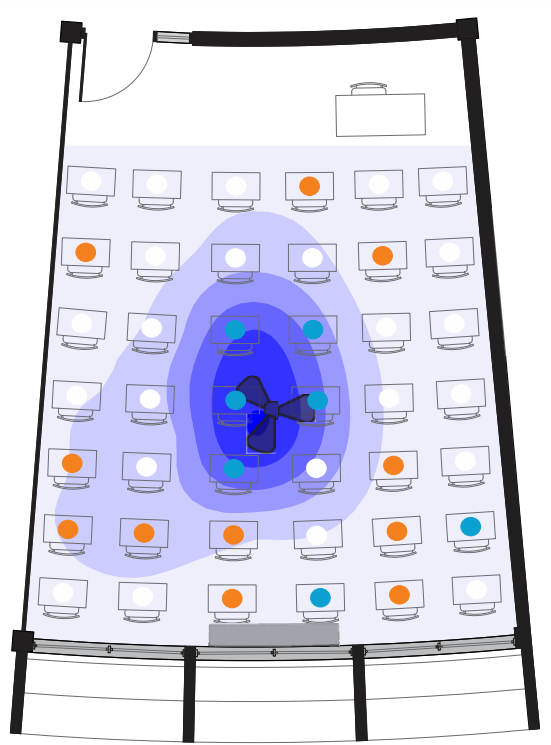

Sala 02

Sem ar condicionado

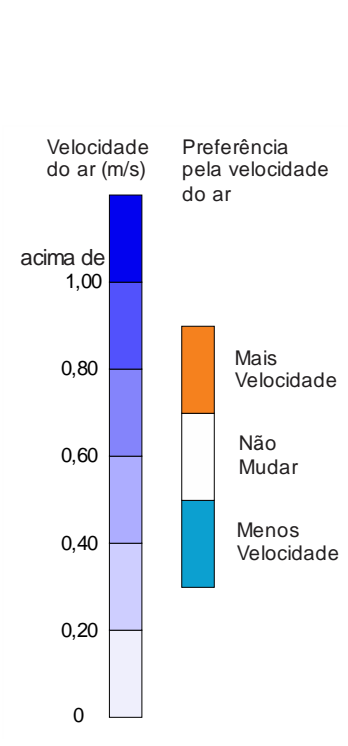

Sala 02

Com ar condicionado

Figura 15 - Votos de conforto térmico

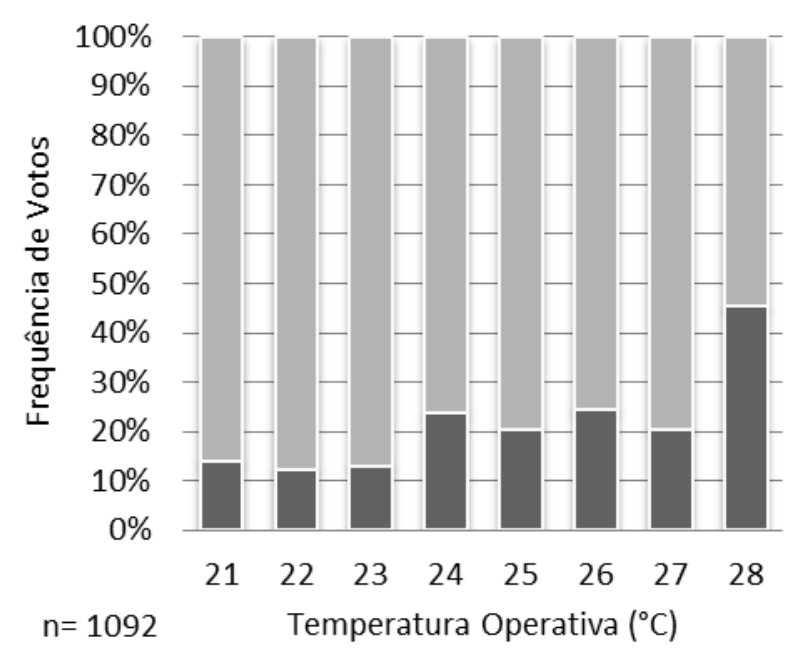

(a) Somente os ventiladores de teto funcionavam

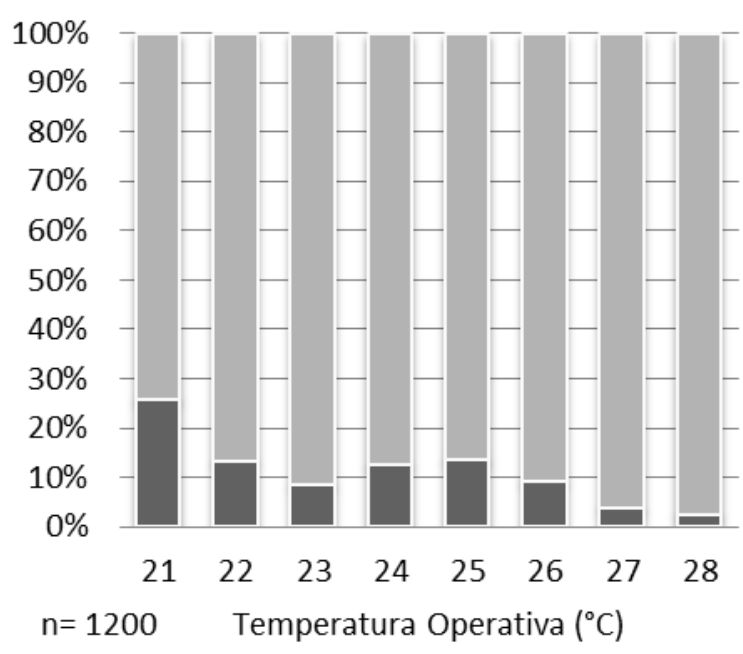

(b) Quando os ventiladores de teto e ar condicionado funcionavam juntos

- Desconfortável $\square$ Confortável

Os resultados para a preferência da velocidade do ar mostraram que, mesmo em situações em que os limites de velocidade do ar ultrapassaram aqueles estipulados em normas de conforto térmico como a internacional ISO 7730 (INTERNATIONAL..., 2005) e as brasileiras em vigor (ABNT, 1990; ABNT, , 2008), ainda havia uma demanda por "maior velocidade do ar". Tais resultados já haviam sido observados por Cândido, De Dear e Lamberts (2011) em uma de clima predominantemente quente, o que pode levar à confirmação de que os limites fixados por essas normas tendem à utilização de set-points mais baixos, e ao consequente consumo energético desnecessário. É importante observar que recentemente, com a última atualização da ASHRAE 55 (INTERNATIONAL..., 2010), esses valores foram expandidos para as situações em que o usuário detém o controle da temperatura e velocidade do ar.

A maior porcentagem de usuários satisfeitos que consideraram o ambiente "confortável" foi 
observada durante as medições em que os ventiladores de teto $\mathrm{e} o$ ar condicionado funcionaram juntos. Nas condições em que $o$ experimento foi realizado, temperaturas operativas entre 24 e $28^{\circ} \mathrm{C}$ foram consideradas "aceitáveis" e "confortáveis" à medida que a temperatura operativa do ar aumentou. Tais resultados indicam a existência de boas oportunidades para ajustes incrementais no set-point de edifícios comerciais com sistemas centrais de climatização artificial, inclusive nos casos em que as janelas não podem ser operadas pelos usuários. Essas oportunidades são viáveis e devem ser incentivadas, a exemplo de programas como o Cool Biz e o Setsuden, no Japão, que fixam limites de temperatura altos em ambientes de trabalho em conjunto com a adaptação da vestimenta e das estratégias de controle individual de temperatura.

\section{Referências}

AMAI, H.; TANABE, S.; AKIMOTO, T.;

GENMA, T. Thermal Sensation and Comfort With Different Task conditioning System. Building and Environment, v. 42, n. 12, p. 3955-3964, 2007.

AMERICAN SOCIETY OF HEATING, REFRIGERATING AND AIR CONDITIONING ENGINEERS. Standard 55: thermal environmental conditions for human occupancy. Atlanta, Georgia, 2010

ARENS, E. et al. Moving Air For Comfort. ASHRAE Journal, v. 51, n. 5, p. 18-29, 2009.

ARENS, E. et al. A Study of Occupant Cooling by Personally Controlled Air Movement. Energy and Buildings, v. 27, n. 1, p. 45-59, 1998.

ASSOCIAÇÃO BRASILEIRA DE NORMAS TÉCNICAS. NBR 16401-2: instalações de arcondicionado: sistemas entrais e unitários: parte 2: parâmetros de conforto térmico. Rio de Janeiro, 2008.

\section{ASSOCIAÇÃO BRASILEIRA DE NORMAS} TÉCNICAS. NR 17: ergonomia. Rio de Janeiro, 1990.

\section{CÂNDIDO, C. Indoor Air Movement}

Acceptability and Thermal Confort in HotHumid Climates. Florianópolis, 2010. Thesis (PhD) - Department of Civil Engineering, Federal University of Santa Catarina. Florianópolis, 2010.

CÂNDIDO, C.; DE DEAR, R.; LAMBERTS, R. Combined Thermal Acceptability and Air Movement Assessments in a Hot Humid Climate. Building and Environment, v. 46, p. 379-385, 2011.
CÂNDIDO, C. et al. Aplicabilidade dos Limites da Velocidade do Ar Para Efeito de Conforto Térmico em Climas Quentes e Úmidos. Ambiente Construído, Porto Alegre, v. 10, n. 4, p. 59-68, out./dez. 2011a.

CÂNDIDO, C. et al. Towards a Brazilian Standard For Naturally Ventilated Buildings: guidelines for thermal and air movement acceptability. Building Research \& Information, v. 39, n. 2, p. 145-153, $2011 b$.

DE DEAR, R. Revisiting an Old Hypothesis of Human Thermal Perception: alliesthesia. Building Research \& Information, v. 39, n. 2, p. 108-117, 2011.

\section{DE VECCHI, R. Condições de Conforto}

Térmico e Aceitabilidade da Velocidade do Ar em Salas de Aula Com Ventiladores de Teto Para o Clima de Florianópolis/SC. Florianópolis, 2011. Dissertação (Mestrado em Engenharia Civil) - Departamento de Engenharia Civil, Universidade Federal de Santa Catarina, Florianópolis, 2011.

DEUBLE, M.; DE DEAR, R. Mixed-Mode Buildings: a double standard in occupants' comfort expectations. Building and Environment, v. 54, n. 8, p. 53-60, 2012.

FANGER, P. O. Thermal Comfort: analysis and applications in environmental engineering. Copenhagen: Darlish Techinical Press, 1970.

GOULART, S.; LAMBERTS, R.; FIRMINO, S. Dados Climáticos Para Projeto e Avaliação Energética de Edificações Para 14 Cidades Brasileiras. Florianópolis: PROCEL/Núcleo de Pesquisa em Construção Civil, UFSC, 1998.

HUANG, L. et al. A Study About the Demand For Air Movement in Warm Environment. Building and Environment, v. 61, p. 27-33, 2013.

INDRAGANTI, M.; OOKA, R.; RIJAL, H. B. Thermal Comfort in Offices in Summer: findings from a field study under the "setsuden" conditions in Tokyo, Japan. Building and Environment, v. 61, p. 114-132, mar. 2013.

INTERNATIONAL ORGANIZATION FOR STANDARDIZATION. ISO 7730: ergonomics of the thermal environment: analytical determination and interpretation of thermal comfort using calculation of the PMV and PPD indices and local thermal comfort criteria. Geneva, 2005.

KHEDARI, J. et al. Thailand Ventilation Comfort Chart. Energy and Buildings, v. 32, p. 245-249, 2000.

\section{LAMBERTS, R. et al. Towards a Brazilian}

Standard on Thermal Comfort. 2013.

Disponível em: 
<http://www.labeee.ufsc.br/sites/default/files/publi cacoes/relatorios_pesquisa/RP_Towards_a_Brazili an_Standard_Complete_Version2013.pdf $>$.

Acesso em: 6 nov. 2013.

MAKHOUL, A.; GHALI, K.; GHADDAR, N. Desk Fans For the Control of the Convection Flow Around Occupants Using Ceiling Mounted Personalized Ventilation. Building and Environment, v. 59, p. 336-348, jan. 2013.

NICOL, J. F. Adaptive Thermal Comfort Standards in the Hot-Humid Tropics. Energy and Buildings, v. 36, n. 7, p. 628-637, 2004.

NICOL, J. F.; ROAF, S. Pioneering New Indoor Temperature Standards: the Pakistan project. Energy and Buildings, v. 23, p. 169-174, 1996.

SEKHAR, S. et al. Findings of Personalized Ventilation Studies in a Hot and Humid Climate. HVAC\&R Research, v. 11, n. 4, p. 603-620, 2005.

TANABE, S.; IWAHASHI, Y.; TSUSHIMA, S. Thermal Comfort and Productivity in Offices Under Mandatory Electricity Savings After Great
East Japan Earthquake. In: WINDSOR CONFERENCE: THE CHANGING CONTEXT OF COMFORT IN AN UNPREDICTABLE WORLD, 7., Cumberland Lodge, 2012. Proceedings... London, 2012.

TANABE, S.; KIMURA, K. Effects of Air Temperature, Humidity, and Air Movement on Thermal Comfort Under Hot and Humid Conditions. ASHRAE Transactions, v. 100, n. 2, p. 953-969, 1994.

TOFTUM, J. Air Movement: good or bad? Indoor Air, v. 14, p. 40-45, 2004.

ZHAI, Y. et al. Comfort Under Personally Controlled Air Movement in Warm and Humid Environments. Building and Environment, v. 65, p. 109-117, 2013.

\section{Agradecimentos}

Este projeto foi financiado pelo Conselho Nacional de Desenvolvimento Científico e Tecnológico (CNPq). Os pesquisadores agradecem ao Departamento de Arquitetura e Urbanismo da Universidade Federal de Santa Catarina, que tornou possível os experimentos de campo nas salas de aula do campus universitário. Em especial, a todos os alunos que concordaram em participar voluntariamente das pesquisas de campo respondendo aos questionários.

Renata De Vecchi

Departamento de Engenharia Civil, Centro Tecnológico | Universidade Federal de Santa Catarina | Campus Universitário, Trindade | Caixa Postal 476 |Florianópolis -SC - Brasil | CEP 88040-900 | Tel.: (48) 3721-5184 | E-mail: renata.vecchi@labeee.ufsc.br

\title{
Christhina Cândido
}

Architectural and Design Science, Faculty of Architecture, Design and Planning | University of Sydney | Wilkinson Building (G04), 148 City Road NSW 2006 |Sydney - Australia | Tel.: +(612) 9351-3206 | E-mail: christhina.candido@sydney.edu.au

\section{Roberto Lamberts}

Departamento de Engenharia Civil, Centro Tecnológico | Universidade Federal de Santa Catarina | E-mail: roberto.lamberts@ufsc.br

\author{
Revista Ambiente Construído \\ Associação Nacional de Tecnologia do Ambiente Construído \\ Av. Osvaldo Aranha, $99-3^{\circ}$ andar, Centro \\ Porto Alegre - RS - Brasil \\ CEP $90035-190$ \\ Telefone: +55 (51) 3308-4084 \\ Fax: +55 (51) 3308-4054 \\ www.seer.ufrgs.br/ambienteconstruido \\ E-mail: ambienteconstruido@ufrgs.br
}

